\title{
Korelasi Penilaian Proses Belajar Model Guided Inquiry Learning dan Guided Discovery Learning Dengan Hasil Belajar Formatif Pada Materi Kesetimbangan Kimia
}

\section{Assessment Correlation of Learning Process Guided Inquiry Learning and Guided Discovery Learning Model With Formative Learning Outcomes in The Topic Chemical Equilibrium}

\author{
F Gusranda $^{1}$ and Z Fitriza ${ }^{*}$ \\ ${ }^{1}$ Pendidikan Kimia, Universitas Negeri Padang, Jl. Prof. Dr. Hamka, Air Tawar Barat, \\ Padang Utara, Sumatera Barat, Indonesia 25171 \\ *zonaliafitriza@gmail.com
}

\section{ARTICLE INFO}

Received 02 January 2020

Revised 16 January 2020

Published 18 May 2020

\begin{abstract}
This study aims to determine the relationship between the assessment of students' learning processes that use the Guided Inquiry Learning and Guided Discovery Learning learning models for formative outcomes. This research uses a quantitative approach with correlation analysis between two research variables. Data on the assessment of student learning processes is obtained from the evaluation given during the learning process, which is at the conclusion stage of each meeting. Student formative learning outcomes data were obtained from diagnostic test questions in the form of reasoned multiple-choice questions and descriptions at the end of chemical equilibrium learning. The results showed the relationship between the assessment of learning processes with student learning outcomes classified as High with a correlation coefficient of 0.81 for class XI Science 1 with "Guided Discovery Learning” learning model and 0.86 for class XI Science 4 with “Guided Inquiry Learning” learning model.
\end{abstract}

\section{KEYWORDS}

Chemical Equilibrium, Formative Assessment, Guided Discovery Learning, Guided Inquiry, Process Assessment

\section{ABSTRAK}

Penelitian ini bertujuan untuk mengetahui adanya hubungan antara penilaian proses belajar siswa yang belajar menggunakan model pembelajaran Guided Inquiry Learning dan Guided Discovery Learning terhadap hasil belajar formatif. Penelitian ini menggunakan pendekatan kuantitatif dengan analisis korelasi antar dua variabel penelitian. Data hasil penilaian proses belajar siswa diperoleh dari evaluasi yang diberikan pada saat proses pembelajaran berlangsung yaitu pada tahap kesimpulan setiap pertemuannya. Data hasil belajar formatif siswa diperoleh dari instrumen soal tes diagnostik berupa pilihan ganda beralasan dan uraian pada akhir pembelajaran kesetimbangan kimia. Hasil penelitian menunjukkan hubungan antara penilaian proses belajar dengan hasil belajar siswa tergolong tinggi dengan nilai koefisien korelasi sebesar 0,81 untuk kelas XI IPA 1 dengan model Guided Discovery Learning dan 0,86 untuk kelas XI IPA 4 dengan model pembelajaran Guided Inquiry Learning.

\section{KATA KUNCI}

Guided Discovery Learning, Guided Inquiry Learning, Kesetimbangan Kimia, Penilaian Formatif, Penilaian Proses 


\section{PENDAHULUAN}

Model pembelajaran Guided Inquiry Learning dan Guided Discovery Learning merupakan salah satu model pembelajaran yang diutamakan dalam implementasi kurikulum 2013. Hal ini berdasarkan pada Peraturan Menteri Pendidikan dan Kebudayaan Nomor 65 Tahun 2013 tentang "standar proses" ${ }^{[1]}$. Kedua model tersebut menekankan pada masalah kontekstual dan aktivitas penyelidikan serta penemuan oleh siswa ${ }^{[2]}$.

Model Guided Inquiry Learning yaitu model pembelajaran yang bisa mendukung siswa dalam menemukan konsep sendiri dalam memperoleh pengetahuanserta sesuaidengantuntutankurikulum $2013^{[3]}$. Sedangkan model Guided Discovery Learning mengarahkan siswa untuk sampai pada suatu kesimpulan dengan memahami arti, konsep, serta hubungan melalui proses intuitif. Pembelajaran tersebut menuntut siswa agar bisa menyampaikan ide atau gagasannya melalui penemuan sehingga siswa akan mampu memahami konsep atau prinsip dengan mudah ${ }^{[4]}$. Model pembelajaran Guided Inquiry Learning dan Guided Discovery Learning pada proses pembelajaran dapat mengembangkan kompetensi sikap dan kompetensi pengetahuan serta keterampilan siswa, agar tercapainya tujuan pembelajaran dengan baik ${ }^{[5]}$.

Materi kesetimbangan dianggap materi yang sulit oleh siswa karena membutuhkan operasi matematika dan pemahaman konsep serta materinya yang bersifat abstrak, sehingga menyebabkan sulitnya untuk mencapai tujuan pembelajaran materi tersebut. Hal ini didukung dari hasil observasi yang dilakukan di SMAN 9 Padang, dari hasil observasi yang dilakukan didapatkan bahwa 53\% siswa masih di bawah KKM pada materi Kesetimbangan Kimia dan dari hasil angket materi kesetimbangan kimia dianggap sulit karena pengaruh kebiasaan belajar siswa dan proses belajar mengajar yang dilakukan guru yang membuat siswa tidak bisa memahami materi kesetimbangan kimia dengan baik.

Berdasarkan dari beberapa hasil penelitian, model pembelajaran Guided Inquiry Learning dan Guided Discovery Learning mempunyai pengaruh terhadap hasil belajar peserta didik dibandingkan pembelajaran konvensional. Hal ini menunjukkan jika proses pembelajaran kedua model tersebut berjalan baik maka akan meningkatkan hasil belajar, namun kalau proses pembelajaran kedua model itu tidak berjalan dengan baik atau sebagaimana mestinya maka juga akan berpengaruh terhadap hasil belajar siswa ${ }^{[6]}$.

Model pembelajaran Guided Inquiry Learning dan Guided Discovery Learning memiliki langkahlangkah yang hampir sama dalam proses pembelajaran yaitu menekankan pada penyelidikan dan penemuan oleh siswa. Tahap terakhir atau penutup dari kedua model tersebut yaitu kesimpulan atau evaluasi ${ }^{[7]}$. Untuk memastikan apakah proses pembelajaran menggunakan model tersebut berjalan dengan baik maka di akhir pembelajaran atau pada tahap penutup diberikan soal evaluasi kepada siswa. Hasil penilaian proses tersebut bisa digunakan untuk acuan mengetahui proses pembelajaran yang telah dilaksanakan berhasil atau tidak. Hasil penilaian proses ini menunjukkan bahwa sintaks Guided Discovery Learning yang terdiri dari "Stimulasi, Identifikasi Masalah, Pengumpulan Data, Pengolahan data, Pembuktian dan Menarik Kesimpulan” adapun sintaks Guided Inquiry Learning yaitu "orientasi, eksplorasi dan pembentukan konsep, aplikasi dan kesimpulan" telah terlaksana sebagaimana yang diharapkan. Hasil penilaian proses yang baik diharapkan sejalan dengan penilaian formatif. Hasil belajar formatif dijadikan sebagai tolak ukur untuk menentukan tingkat keberhasilan proses pembelajaran secara keseluruhan. Untuk itu perlu diketahui bagaimana korelasi proses pembelajaran menggunakan model pembelajaran Guided Inquiry Learning dan Guided Discovery Learning dengan nilai formatifnya.

\section{METODE}

Pendekatan yang digunakan dalam penelitian ini adalah pendekatan kuantitatif dengan desain penelitian korelasional karena melihat adanya hubungan hasil proses belajar pada siswa dengan hasil belajar formatif siswa ${ }^{[8]}$. Penelitian ini dilaksanakan di SMAN 9 Padang pada siswa kelas XI IPA.

Pengambilan sampel yaitu teknik simple random sampling karena populasi berdistribusi normal dan memiliki variansi homogen. Data dikumpulkan dari hasil penilaian proses belajar dan hasil belajar formatif siswa yang diperoleh dari dua kelas yang berbeda. Data hasil penilaian proses diperoleh dari hasil evaluasi di akhir pembelajaran sedangkan hasil belajar formatif diperoleh dari nilai ujian materi kesetimbangan kimia di akhir pembelajaran atau nilai UH siswa. Proses pembelajaran pada kedua kelas tersebut dilaksanakan dengan model pembelajaran yang berbeda, yaitu masing-masing dengan model Guided Inquiry Learning dan Model pembelajaran Guided Discovery Learning. Instrumen penelitian yang digunakan yaitu soal uraian untuk mengukur penilaian proses belajar siswa pada tahap evaluasi dan soal diagnostik berupa pilihan ganda beralasan dan uraian untuk mengukur hasil belajar formatif siswa.

Data yang terkumpul yaitu data hasil penilaian proses belajar dan data hasil belajar formatif siswa. Data dari kedua kelas tersebut kemudian masingmasing dianalisis dengan uji korelasi product moment menggunakan analisis statistik inferensial dengan taraf signifikan $0,05(\mathrm{p}<0,05)^{[9]}$.

$$
r_{x y}=\frac{n \sum X Y-\left(\sum X\right)\left(\sum Y\right)}{\sqrt{\left\{n \sum X^{2}-\left(\sum X\right)^{2}\right\}\left\{n \sum Y^{2}-\left(\sum Y\right)^{2}\right\}}}
$$

Keterangan:

$\mathrm{r}_{\mathrm{xy}}=$ koefisien korelasi antara $\mathrm{X}$ dan $\mathrm{Y}$

$\mathrm{N}^{\mathrm{xy}}=$ jumlah subjek 
$\mathrm{X}=$ Hasil penilaian proses belajar

$\mathrm{Y}=$ Hasil belajar siswa

$\sum \mathrm{X}=$ jumlah nilai hasil proses belajar

$\sum \mathrm{Y}=$ jumlah nilai hasil belajar

$\sum \mathrm{X}^{2}=$ jumlah kuadrat proses belajar

$\sum \mathrm{Y}^{2}=$ jumlah kuadrat hasil belajar

$\sum \mathrm{XY}=$ jumlah perkalian

Nilai koefisien korelasi antara penilaian proses belajar dengan hasil belajar formatif siswa yang diperoleh dari kedua model pembelajaran tersebut, selanjutnya diinterpretasikan sesuai dengan kriteria pada Tabel 1.

Tabel 1. Interpretasi Koefisien Korelasi ${ }^{[10]}$.

\begin{tabular}{c|c}
$\begin{array}{c}\text { Interval Koefi- } \\
\text { sien }\end{array}$ & Tingkat Hubungan \\
\hline 0,00 & Tidak Ada Korelasi \\
\hline $0,01-0,20$ & Korelasi Sangat Lemah \\
\hline $0,21-0,40$ & Korelasi Lemah \\
\hline $0,41-0,70$ & Korelasi Sedang \\
\hline $0,71-0,99$ & Korelasi Tinggi \\
\hline 1,00 & Korelasi Sempurna
\end{tabular}

\section{HASIL DAN DISKUSI}

\subsection{Data Hasil Penelitian}

Hasil penelitian yang dilakukan di SMAN 9 Padang pada kelas XI IPA 1 dan XI IPA 4, diperoleh tiga hasil penilaian proses belajar dan satu hasil belajar formatif siswa pada masing-masing kelasnya. Proses pembelajaran dilaksanakan dengan model pembelajaran yang berbeda, yaitu kelas XI IPA 1 dengan model Guided Discovery Learning dan kelas XI IPA 4 dengan model Guided Inquiry Learning.

\subsubsection{Hasil Penilaian Proses Belajar dan Hasil \\ Belajar Formatif}

Jumlah rekapitulasi hasil penilaian proses dan formatif siswa dapat dilihat pada Tabel 2. Penilaian proses belajar siswa dilaksanakan di akhir setiap pertemuan pembelajaran atau pada saat tahap penutup dalam proses pembelajaran (Evaluasi). Penilaian proses belajar dilakukan sebanyak tiga kali masing-masing setiap pertemuan. Penilaian berdasarkan soal yang sudah sesuai dengan indikator pencapaian kompetensi setiap pertemuannya. Hasil penilaian proses belajar tersebut dirata-ratakan dan dijadikan sebagai variabel $\mathrm{X}$.

Hasil penilaian proses pada kelas XI IPA 4 dengan model Guided Inquiry Learning terlihat lebih baik dari pada kelas XI IPA 1 dengan model pembelajaran Guided Discovery Learning. Hal ini dibuktikan dengan hasil penilaian proses pada kelas XI IPA 4 yang memperoleh nilai 91-100 sebesar 55\%.

Penelitian ini juga mengukur nilai hasil belajar formatif siswa yang dilaksanakan di akhir pembelajaran. Hasil belajar formatif siswa dengan model Guided Inquiry Learning mempunyai hasil belajar yang lebih baik dibandingkan dengan model pembelajaran Guided Discovery Learning.

Tabel 2 menunjukkan bahwa 26\% hasil belajar formatif siswa pada model pembelajaran Guided Discovery Learning ada pada rentang 81-90 dan 34\% berada pada rentang 91-100 sedangkan hasil belajar siswa dengan model Guided Inquiry Learning ada 17\% siswa yang berada pada rentang nilai $81-90$ dan $40 \%$ siswa berada pada rentang 91-100.

\subsubsection{Hasil Analisis Korelasi Antara Penilaian Proses Belajar dengan Hasil Belajar Formatif Siswa Pada Masing-Masing Kelas}

Hubungan antara penilaian proses belajar siswa dengan hasil belajar formatif siswa dapat dilihat menggunakan uji korelasi. Analisis dilakukan dengan uji korelasi product moment dengan analisis statistik inferensial pada taraf signifikansi 0,05. Rata-rata penilaian proses belajar siswa adalah variabel $\mathrm{X}$ dan Hasil belajar formatif siswa merupakan variabel Y, selanjutnya dimasukkan dalam rumus uji korelasi product moment.

$$
r_{x y}=\frac{n \sum X Y-\left(\sum X\right)\left(\sum Y\right)}{\sqrt{\left\{n \sum X^{2}-\left(\sum X\right)^{2}\right\}\left\{n \sum Y^{2}-\left(\sum Y\right)^{2}\right\}}}
$$

Tabel 2. Hasil Penilaian Proses dan Formatif Siswa.

\begin{tabular}{c|c|c|c|c|c|c|c|c|c}
\multirow{2}{*}{$\begin{array}{c}\text { Interval } \\
\text { Skor }\end{array}$} & \multicolumn{4}{|c|}{ Model Guided Inquiry Learning } & \multicolumn{3}{c}{ Model Guided Discovery Learning } \\
\cline { 3 - 9 } & & Penilaian Proses & \multicolumn{2}{c}{ Penilaian Formatif } & \multicolumn{2}{c}{ Penilaian Proses } & \multicolumn{2}{c}{ Penilaian Formatif } \\
\cline { 3 - 9 } & & F & \% & F & \% & F & \% & F & $\%$ \\
\hline 1 & $21-30$ & 0 & 0 & 0 & 0 & 0 & 0 & 2 & 6 \\
\hline 2 & $31-40$ & 0 & 0 & 0 & 0 & 0 & 0 & 2 & 6 \\
\hline 3 & $41-50$ & 0 & 0 & 2 & 6 & 0 & 0 & 0 & 0 \\
\hline 4 & $51-60$ & 0 & 0 & 1 & 3 & 0 & 0 & 1 & 3 \\
\hline 5 & $61-70$ & 1 & 3 & 0 & 0 & 0 & 0 & 2 & 6 \\
\hline 6 & $71-80$ & 2 & 6 & 10 & 29 & 4 & 11 & 7 & 20 \\
\hline 7 & $81-90$ & 12 & 36 & 6 & 17 & 13 & 37 & 9 & 26 \\
\hline 8 & $91-100$ & 18 & 55 & 14 & 40 & 18 & 51 & 12 & 34
\end{tabular}


Berdasarkan dari analisis data tersebut diperoleh hasil koefisien korelasi sebesar $\mathbf{0 , 8 1}$ untuk kelas XI IPA 1 dengan model pembelajaran Guided Discovery Learning dan 0,86 untuk kelas XI IPA 4 dengan model pembelajaran Guided Inquiry Learning.

\subsection{Pembahasan Hasil Penelitian}

Penilaian proses dilaksanakan pada saat proses pembelajaran itu berlangsung. Penilaian proses harus menunjukkan kinerja kemampuan siswa dan menilai perolehan penerapan pengetahuan melalui proses pembelajaran. Langkah-langkah dalam penilaian proses yaitu perencanaan, pengumpulan informasi, pengolahan, dan penggunaan informasi yang dilaksanakan pada saat proses pembelajaran. Penilaian proses bisa dijadikan sebagai acuan dalam pencapaian tujuan pembelajaran dengan menitikberatkan pada tingkat efektivitas pembelajaran. Tujuan dari penilaian proses belajar yaitu untuk melihat kegiatan belajar, terutama efisiensi, dan keefektifitasannya dalam mencapai tujuan pembelajaran ${ }^{[11]}$. Pada penelitian ini penilaian proses belajar dilakukan sebanyak tiga kali di akhir pertemuan pada saat proses pembelajaran berlangsung. Rata-rata penilaian proses belajar siswa dari masing-masing kelas tergolong baik, karena terdapat $88 \%$ siswa yang mempunyai nilai pada interval 81-100 di kelas dengan model Guided Discovery Learning dan 91\% siswa di kelas dengan model Guided Inquiry Learning. Berdasarkan data tersebut terlihat ternyata proses belajar dengan model pembelajaran Guided Inquiry Learning lebih baik dari model pembelajaran Guided Discovery Learning.

Penilaian formatif bertujuan untuk memperbaiki proses pembelajaran, mengetahui keberhasilan proses pembelajaran dan mendeskripsikan kecakapan belajar serta menentukan tindak lanjut dari hasil penilaian tersebut ${ }^{[12]}$. Hasil belajar siswa pada penelitian ini juga tergolong baik, terdapat $80 \%$ siswa yang mempunyai nilai $>75$ pada kelas dengan model Guided Discovery Learning dan $86 \%$ pada kelas dengan model Guided Inquiry Learning. Dari hasil tersebut ternyata hasil belajar siswa dengan model pembelajaran Guided Inquiry Learning lebih baik dari model pembelajaran Guided Discovery Learning.

Berdasarkan uraian tersebut bisa diketahui bahwa ketika proses belajar dalam pembelajaran terlaksana dengan baik maka hasil belajar formatif pada peserta didik juga akan baik. Hal ini dapat dibuktikan dari uji nilai koefisien korelasi untuk melihat hubungan antara penilaian proses belajar (X) dan penilaian hasil belajar siswa (Y). Berdasarkan analisis data tersebut diperoleh nilai koefisien korelasi sebesar 0,81 untuk kelas XI IPA 1 dengan model Guided Discovery Learning dan 0,86 untuk kelas XI IPA 4 dengan model Guided Inquiry Learning. Interpretasi dari nilai koefisien korelasi tersebut menunjukkan tingkat hubungan yang Tinggi dan terjadi korelasi positif antara penilaian proses belajar $(\mathrm{X})$ dan penilaian hasil belajar siswa (Y). Dengan demikian dapat diketahui bahwa adanya hubungan yang tinggi antara penilaian proses belajar $(\mathrm{X})$ dan penilaian hasil belajar siswa (Y). Semakin meningkatnya hasil penilaian proses belajar pada siswa $(\mathrm{X})$ maka nilai hasil belajar (Y) siswa juga akan semakin meningkat atau bisa disebut sebagai korelasi positif. Nilai koefisien korelasi dengan model Guided Inquiry Learning lebih tinggi dari model Guided Discovery Learning.

\section{SIMPULAN}

Berdasarkan dari analisis data yang diperoleh nilai koefisien korelasi sebesar 0,81 untuk kelas XI IPA 1 dengan model Guided Discovery Learning dan 0,86 untuk kelas XI IPA 4 dengan model Guided Inquiry Learning. Meskipun hanya berbeda sedikit, koefisien korelasi dengan model Guided Inquiry Learning lebih tinggi dari model Guided Discovery Learning. Semakin meningkat hasil penilaian proses belajar siswa (X) maka nilai hasil belajar formatif siswa (Y) juga akan semakin meningkat.

\section{REFERENSI}

1. Kemendikbud. Materi Pelatihan Implementasi Kurikulum 2013. Jakarta: Kemendikbud; 2014.

2. Sirait M. Model Pembelajaran Berbasis Discovery-Inkuiri dan Kontribusinya Terhadap Penguatan Kualitas Pembelajaran di Sekolah Dasar. AR-RIAYAH I Pendidik Dasar 2017;1(2):155.

3. Hanson DM. Designing Process-Oriented Guided-Inquiry Activities. Pacific Crest 2005;(2nd edition).

4. Solichin MM. Penerapan Model Pembelajaran Inquiry Discovery. Tadris 2017;2(12):2.

5. Sufairoh. Pendekatan Saintifik \& Model Pembelajaran K-13. J Pendidik Prof 2016;5(3):116-25.

6. Makhfidah Eni. Efektivitas Model Pembelajaran Inkuiri Terbimbing Terhadap Hasil Belajar Peserta Didik Pada Materi Kesetimbangan Kimia Kelas XI di MAN 2 Jombang. I Chem Educ 2019;8(3):288-293.

7. Muhammad M, Nurdyansyah N. Pendekatan Pembelajaran Saintifik. Sidoarjo: 2015.

8. Mukhtar R. Hubungan Motivasi Belajar Dengan Hasil Belajar Pada Mata Pelajaran Seni Budaya Bidang Seni Musik Siswa Kelas X SMA Piri 1 Yogyakarta. Pendidik Seni Budaya 2015;4(2):23.

9. Bertan CV. Pengaruh Pendayagunaan Sumber Daya Manusia (Tenaga Kerja) Terhadap Hasil Pekerjaan (Studi Kasus Perumahan Taman Mapanget Raya. Sipil Statik 2016;4(1):13-20.

10. Astuti CC. Analisis Korelasi untuk Mengetahui Keeratan Hubungan antara Keaktifan Mahasiswa dengan Hasil Belajar Akhir. Orig Res Artic 2017;1(4):1-7.

11. Guntur G. Penilaian Berbasis Kinerja (Performance-Based). Pendidik Jasm Indones 2014;10(4):15-22.

12. Salamah U. Penjaminan Mutu Penilaian Pendidikan. Evaluasi 2018;2(1):274-93. 